\title{
Identification of a PH domain-containing protein which is localized to crystalloid bodies of Plasmodium ookinetes
}

\author{
Rachaneeporn Jenwithisuk 1,2, Niwat Kangwanrangsan33, Mayumi Tachibana', Amporn Thongkukiatkul ${ }^{4}$, \\ Hitoshi Otsuki ${ }^{5}$, Jetsumon Sattabongkot ${ }^{2}$, Takafumi Tsuboi ${ }^{6}$, Motomi Torii ${ }^{1}$ and Tomoko Ishino ${ }^{1 *}$ (D)
}

\begin{abstract}
Background: For the success of the malaria control and eradication programme it is essential to reduce parasite transmission by mosquito vectors. In the midguts of mosquitoes fed with parasite-infected blood, sexual-stage parasites fertilize to develop into motile ookinetes that traverse midgut epithelial cells and reside adjacent the basal lamina. Therefore, the ookinete is a promising target of transmission-blocking vaccines to break the parasite lifecycle in mosquito vectors. However, the molecular mechanisms of ookinete formation and invasion of epithelial cells have not been fully elucidated. A unique structure called the crystalloid body has been identified in the ookinete cytoplasm by electron microscopy, but its biological functions remain unclear.
\end{abstract}

Methods: A recombinant protein of a novel molecule, designated as crystalloid body specific PH domain-containing protein of Plasmodium yoelii (PyCryPH), was synthesized using a wheat germ cell-free system. Specific rabbit antibodies against $P y C r y P H$ were obtained to characterize the expression and localization of PyCryPH during sexual-stage parasite development. In addition, PyCryPH knockout parasites were generated by targeted gene disruption to examine PyCryPH function in mosquito-stage parasite development.

Results: Western blot and immunofluorescence assays using specific antibodies showed that PyCryPH is specifically expressed in zygotes and ookinetes. By immunoelectron microscopy it was demonstrated that PyCryPH is localized within crystalloid bodies. Parasites with a disrupted PyCryPH gene developed normally into ookinetes and formed oocysts on the basal lamina of midguts. In addition, the number of sporozoites residing in salivary glands was comparable to that of wild-type parasites.

Conclusions: $\mathrm{CryPH}$, containing a signal peptide and $\mathrm{PH}$ domain, is predominantly expressed in zygotes and ookinetes and is localized to crystalloid bodies in P. yoelii. CryPH accumulates in vesicle-like structures prior to the appearance of typical crystalloid bodies. Unlike other known crystalloid body localized proteins, CryPH does not appear to have a multiple domain architecture characteristic of the LAP/CCP family proteins. Although CryPH is highly conserved among Plasmodium, Babesia, Theileria, and Cryptosporidium, PyCryPH is dispensable for the development of invasive ookinetes and sporozoites in mosquito bodies.

Keywords: Plasmodium yoelii, Ookinete, Zygote, Crystalloid body, PH domain

\footnotetext{
*Correspondence: tishino@m.ehime-u.ac.jp

${ }^{1}$ Division of Molecular Parasitology, Proteo-Science Center, Ehime University, Toon, Ehime 791-0295, Japan

Full list of author information is available at the end of the article
} 


\section{Background}

Malaria is caused by the transmission of Plasmodium spp. to mammalian hosts by Anopheles mosquitoes. Malaria transmission begins with the uptake of infected blood containing sexual-stage gametocyte parasites, which leads to rapid gametogenesis followed by fertilization to form zygotes. The parasites then transform into motile ookinetes that migrate through the midgut epithelium to the basal lamina. At this site the ookinetes transform into oocysts, within which thousands of sporozoites develop [1]. Upon their release into haemolymph, sporozoites invade salivary glands, to be injected into mammalian hosts together with saliva [2,3]. Ookinete formation and its traverse of midgut epithelium are indispensable events in the series of steps for parasite transmission via mosquito vectors. Two infectious forms of Plasmodium, merozoites and sporozoites, form a parasitophorous vacuole (PV) during the invasion of target cells and subsequent maturation within the PV space. In contrast, ookinetes traverse midgut epithelial cells without forming a PV, and reside extracellularly adjacent the basal lamina $[4,5]$. Ookinetes are morphologically distinct from the other two invasive forms, merozoites and sporozoites, in that they lack rhoptries and contain crystalloid bodies in their cytosol [6-8]. Crystalloid bodies have been described as spherical organelles with a honeycomblike or viral inclusion-like structure [9-12]. Crystalloid bodies are observed in numerous parasites in the phylum Apicomplexa, such as Plasmodium [10, 11, 13, 14], Haemoproteus [11], Leucocytozoon [11, 15, 16], Hepatozoon [17], Haemolivia [18], Isospora [19-21], Hammondia [22], Cryptosporidium [23, 24], and Eleutheroschizon [25]. Although crystalloid bodies have been described for their characteristic structure, their formation and function remain largely unknown. Members of the LCCL lectin adhesive-like protein (LAP) family, which share a conserved architecture of multiple predicted adhesive domains including the LCCL (Limulus coagulation factor C, Coch-5b2 and Lgl1) domain, have been demonstrated to localize to crystalloid bodies of Plasmodium berghei ookinetes [14, 26, 27]. These molecules are categorized as the CCp family in Plasmodium falciparum and were shown to form multi-protein complexes in sexual-stage parasites [28-32]. Disruption of $L A P / C C p$ genes, either individually or in pairs, give rise to similar loss-of-function phenotypes; specifically, a failure of oocyst development to produce infective sporozoites (see Table 1) $[14,29,30,33-37]$. These data suggested that crystalloid bodies play an important role for subsequent sporozoite formation and/or its invasive ability, but further studies are needed to understand the specific functions of crystalloid bodies. In the course of screening for novel secreted or membrane proteins of sexual-stage parasites based on microarray data of $P$. falciparum stage-specific gene expression [38] and P. berghei AP2-G2 KO gametocyte gene expression [39], a protein with a pleckstrin homology (PH) domain, which is localized in the crystalloid bodies of ookinetes, was identified. In this study, this protein, designated as $\mathrm{CryPH}$, was characterized in the rodent malaria parasite line Plasmodium yoelii 17XNL (PyXNL). In addition, the role of $P y C r y P H$ during parasite development in mosquito bodies was examined by generating PyCryPH gene-disrupted parasites.

\section{Methods}

\section{Parasites and mosquitoes}

Cryopreserved $P y \mathrm{XNL}$ infected erythrocytes were intraperitoneally injected into 4-6-week-old ICR female mice (CLEA Japan, Tokyo, Japan) to obtain asexual- and sexual-stage parasites. Mice were kept in a room with a temperature of $24{ }^{\circ} \mathrm{C}$ under a $12 \mathrm{~h}$ light/12 h dark cycle. For mosquito feeding experiments, PyXNL-infected mouse erythrocytes diluted with RPMI 1640 (Wako Pure Chemical, Osaka, Japan) were fed to Anopheles stephensi SDA500 mosquitoes through a membrane-feeding apparatus. Fully engorged mosquitoes were selected and kept at $24{ }^{\circ} \mathrm{C}$ until dissection. On days 10 and 17 post-feeding, midguts and salivary glands were collected by dissection to count the numbers of oocysts and sporozoites, respectively. All animal experimental protocols were approved by the Institutional Animal Care and Use Committee of Ehime University, and the experiments were conducted according to the Ethical Guidelines for Animal Experiments of Ehime University.

\section{In silico screening}

To identify secreted or membrane-anchored proteins in sexual-stage parasites, candidate genes were selected using information within the PlasmoDB database [40] as follows: (1) identification of transcripts whose levels in $P$. falciparum gametocytes are $>3$-fold greater than in P. falciparum sporozoites, and are not abundant (below the 50th percentile) in P. falciparum schizonts [38]; (2) possession of a secondary structure containing a signal peptide and/or transmembrane domain; (3) orthologues are conserved among Plasmodium spp.; and (4) P. berghei genes transcripts in wild-type gametocytes are $>100$-fold more than those in AP2-G2 KO gametocytes [39]. Sixtytwo genes were selected by the first two criteria, and of these 32 genes were selected as candidates expressed in the sexual-stage parasites as predicted secreted- or membrane anchored-proteins.

\section{Recombinant proteins and antiserum production}

Recombinant $\mathrm{PyCryPH}$ ( $\mathrm{rCryPH})$ was produced using the wheat germ cell-free protein synthesis system 


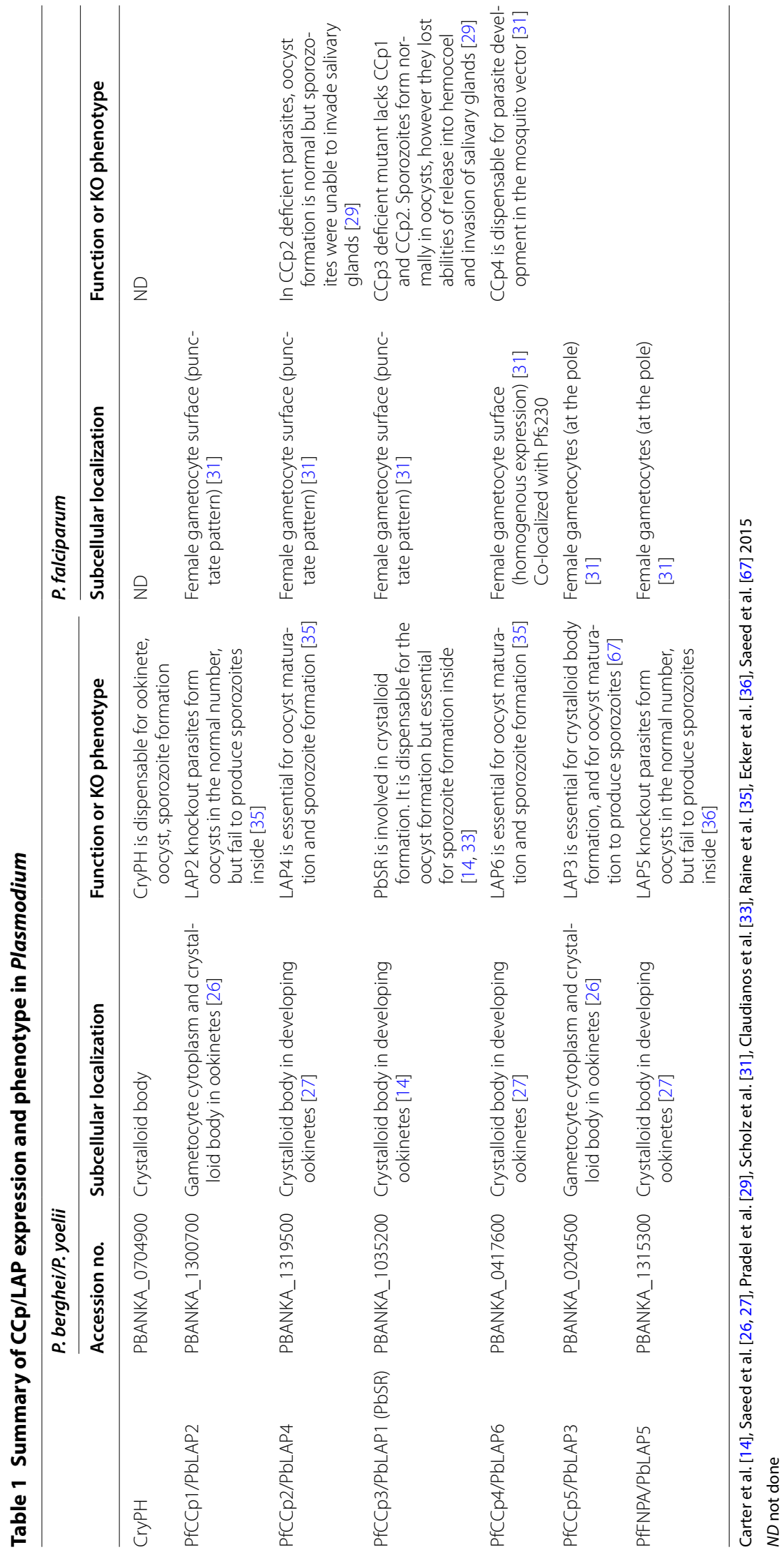


(CellFree Sciences, Matsuyama, Japan) as described $[41,42]$. Briefly, a DNA fragment encoding $P y C r y P H$ (PY17X_0705200) without the N-terminal signal peptide (amino acids 19-287 of CryPH) was amplified from PyXNL genomic DNA using Phusion high-fidelity DNA polymerase (New England BioLabs, Ipswich, MA, USA) with a primer pair $5^{\prime}$-ctcgagCATAAAAATTTCTCA AGAAGAAATAATTAC-3' ${ }^{\prime}$ and $5^{\prime}$-ggatccTCATTTGAG AGAAATATTTGGATTGC-3'. The amplified $P y C r y P H$ DNA fragment was cloned into the pEU-E01-HisGST (TEV)-N2 vector (CellFree Sciences) between the XhoI and BamHI recognition sites. The DNA sequence of the insert was confirmed using an ABI PRISM 3100 Genetic Analyzer and a BigDye Terminator v1.1 Cycle Sequencing kit (Applied Biosystems, Foster City, CA, USA). PyCryPH GST fusion recombinant protein was expressed using the wheat germ cell-free protein synthesis system (CellFree Sciences), and then tag-free $\mathrm{rCryPH}$ was purified by on-column cleavage using AcTEV protease (Invitrogen, Carlsbad, CA, USA) and the glutathione-Sepharose 4B column (GE Healthcare, Camarillo, CA, USA). Protein synthesis was confirmed by separation on SDS-PAGE under reducing condition and visualized with Coomassie Brilliant Blue protein staining. Protein concentration was determined using a Bradford protein assay kit (Bio-Rad Laboratories, Hercules, CA, USA).

To generate antibodies against $\mathrm{CryPH}$, a Japanese white rabbit was immunized subcutaneously with $250 \mu \mathrm{g}$ rCryPH with Freund's complete adjuvant followed by two booster immunizations with $250 \mu \mathrm{g}$ rCryPH with Freund's incomplete adjuvant. All immunizations were done at 3-week intervals, and antisera were collected 14 days after the last immunization (Kitayama labes Co. Ltd. Ina, Japan). Anti-CryPH rabbit antibodies were affinity purified using a HiTrap NHS-activated HP column (GE Healthcare) coupled to rCryPH.

\section{Construction of GFP-tagged CryPH expressing parasites and $\mathrm{CryPH}$ disrupted parasites}

To generate GFP-tagged CryPH expressing parasites (CryPH-GFP), the PyCryPH/PY17X_0705200 locus was replaced by double-crossover homologous recombination method with the coding region of $\mathrm{CryPH}$ fused in-frame with a GFP coding sequence at the C-terminus. As shown in Additional file 1: Figure S1a, two homologous recombination cassettes-the $\mathrm{C}$-terminal region of $\mathrm{CryPH}$ coding sequence $(\mathrm{CryPH}-\mathrm{C})$ and the $3^{\prime}$-UTR of CryPH (CryPH-3')-were sub-cloned into the pGFPDT-B12 vector, which was modified from pPbDT3U-B12 [43] to contain a GFP coding sequence. An 807 bp DNA fragment corresponding to CryPH$\mathrm{C}$ and an $849 \mathrm{bp}$ fragment corresponding to $\mathrm{CryPH}-$ $3^{\prime}$ were PCR amplified from $P y X N L$ genomic DNA using the following primers: CryPH.F1 (5'-ctcgagCAT AAAAATTTCTCAAGAAGAAATAATTAC- $3^{\prime}$ ) plus CryPH.NheI.R (5'-gctagcTTTGAGAGAAATATT TGGATTGC-3'); and CryPH.3UTR.SalI.F (5'-gtcgacCGAATAGGGAAAAAAAAATCTCC- $3^{\prime}$ ) plus CryPH.3UTR.XhoI.R (5'-ctcgagGGGTATCTGACT TTATATTGAGC-3'). For transgenic parasite selection, human dihydrofolate reductase gene (hDHFR) coding sequence was introduced into the vector by Gateway technology (Invitrogen) using pHDEF-1-mh-R12 [44].

The same strategy as described above was applied to generate $\mathrm{CryPH}$-disrupted parasites $(\triangle \mathrm{CryPH})$. Instead of CryPH-C, the $5^{\prime}$-UTR of CryPH (CryPH-5') was used as one of the cassettes for homologous recombination (Additional file 1: Figure S1b). A 965 bp fragment corresponding to $\mathrm{CryPH}-5^{\prime}$ was amplified by $\mathrm{PCR}$ with the following primers: CryPH.5UTR.XhoI.F (5'-ctcgagGGA ATAGCTATGCATATATGCG-3') and CryPH.5UTR. BamHI.R (5'-ggatccCAATTTACAATAACAACAAAA TATGG- $3^{\prime}$ ). The fragments CryPH- $5^{\prime}$ and $\mathrm{CryPH}-3^{\prime}$ were cloned into the pPbDT3U-B12 transgenic vector. The drug-resistant cassette was inserted as described above. To prepare control parasites (CryPH-cont), the same drug-resistant cassette was integrated just after the $\mathrm{PyCryPH}$ gene by homologous recombination (Additional file 1: Figure S1c). Two homologous recombination cassettes $\mathrm{CryPH}-\mathrm{C}$, conjugated to the $3^{\prime} \mathrm{UTR}$ of $\mathrm{PbD}$ HFR/ts, and CryPH- $3^{\prime}$ were cloned into the pPbDT3U$\mathrm{B} 12$ vector as described above.

Transfection of PyXNL parasites (PyWT) was performed as described with some modification [45, 46]. Briefly, PyWT schizont-infected erythrocytes were enriched by density gradient centrifugation and transfected with linearized plasmid DNA using the Nucleofector 2b (Lonza Japan, Tokyo, Japan) with human T cell solution under program U-33. After electroporation, infected erythrocytes were intravenously injected into 4-week-old ICR female mice. Drug selection was initiated $24 \mathrm{~h}$ after inoculation by adding $70 \mu \mathrm{g} / \mathrm{mL}$ pyrimethamine to the drinking water. The integration of the target DNA fragment was detected by genotyping PCR, using attB1-link.AvF (5'-CTAGACAAGTTTGTACAAAAA AGCAGG-3') and PY00516.R (5'-TTGATAACATGC TATCATGTCG-3'). The wild-type locus was detected by PCR using PyCryPH.F2 (5'-CCGATATACCAAAGC ATTCAAC-3 ${ }^{\prime}$ ) and CryPH.3UTR.XhoI.R (5'-ctcgagGGG TATCTGACTTTATATTGAGC- $3^{\prime}$ ). Non-linearized plasmid (episomal form) was detected by PCR using PyCryPH.3UTR.F1 (5'-GCACACAAATATGTGTAT CAATG- $3^{\prime}$ ) and PbDT3U.R1 (5'-ACAGTTATAAATACA ATCAATTGG-3'). A clone of CryPH-GFP, two independent clones of $\triangle \mathrm{CryPH}$, and a clone of $\mathrm{CryPH}$-cont were isolated by limiting dilution. 


\section{In vitro ookinete culture}

For in vitro ookinete culture, cryopreserved PyXNLinfected blood was intraperitoneally injected into ICR mice pretreated with $1.2 \mathrm{mg}$ phenylhydrazine to induce reticulocyte production. Infected blood with a high number of gametocytes collected from these mice was diluted fourfold with suspended animation medium (9 $\mathrm{mM}$ glucose, $8 \mathrm{mM}$ Tris-base, $138 \mathrm{mM}$ sodium chloride, pH7.3) pre-warmed at $37{ }^{\circ} \mathrm{C}$. After passing through a CF11 column to deplete white blood cells, the infected erythrocytes were resuspended with 20 volumes of ookinete culture medium (RPMI 1640 medium containing 20\% heat inactivated fetal calf serum, $0.367 \mathrm{mM}$ hypoxanthine, $25 \mathrm{mM}$ 4-(2-hydroxyethyl)-1-piperazineethanesulfonic acid (HEPES) and $5 \mathrm{IU} / \mathrm{mL}$ heparin, $\mathrm{pH}$ 8.3), and incubated at $24{ }^{\circ} \mathrm{C}$ [44]. At $0,1,4$, and 14-18 h after incubation, equal volumes of cultured parasites were collected for further analyses. To enrich sexual-stage parasites, density gradient centrifugation using $14 \%(\mathrm{w} / \mathrm{v})$ histodenz (Sigma-Aldrich Company Ltd, St. Louis, MO, USA) was performed [47]. The parasites were collected on the interface and washed twice with ice-cold PBS containing protease inhibitors (PBS-PI; Roche Applied Science, Penzberg, Germany). Giemsa-stained smears on glass slides were used to assess the stage and purity of cultured parasites. The number of parasites obtained after purification were counted in a hemocytometer.

\section{Western blotting analysis}

Parasite lysates (gametocytes, ookinetes, and schizonts) were prepared by repeated freeze-thaw cycles in $1 \%$ Triton X-100 in PBS-PI and heated in SDS-PAGE loading buffer in the absence or presence of $4 \%$ B-mercaptoethanol at $95{ }^{\circ} \mathrm{C}$ for $5 \mathrm{~min}$. Sporozoites were collected from midguts of infected mosquitoes and heated in SDS-PAGE loading buffer containing 4\% ß-mercaptoethanol. Equivalent numbers of parasites per lane were subjected to electrophoresis in a 5-20\% gradient polyacrylamide gel (ATTO, Tokyo, Japan) and then transferred to a polyvinylidene fluoride membrane (BioRad). Membranes were blocked in Blocking One (Nacalai tesque, Kyoto, Japan) overnight at $4{ }^{\circ} \mathrm{C}$, followed by immunostaining with antiCryPH antibodies (1: 2000) for $1 \mathrm{~h}$ at room temperature. Anti-Pys 25 mouse monoclonal antibodies (mAb) were used as a zygote/ookinete marker [48]. Anti-RAMA antiserum (1: 2000) was used as a positive marker for schizonts and sporozoites [49]. Membranes were then stained with secondary antibodies (goat anti-rabbit IgG or goat anti-mouse IgG) conjugated to horseradish peroxidase (HRP; Thermo Fisher Scientific, Waltham, MA, USA; 1:20,000) for $30 \mathrm{~min}$ at room temperature. Chemiluminescent detection was performed by adding Immobilon
Western Chemiluminescence HRP substrate (Merck Millipore, Darmstadt, Germany).

\section{Immunofluorescence assay (IFA)}

Smears of cultured PyXNL parasites were fixed on glass slides with ice-cold acetone for $5 \mathrm{~min}$ and blocked with PBS containing $5 \%$ nonfat milk at $37{ }^{\circ} \mathrm{C}$ for $30 \mathrm{~min}$. They were then incubated with rabbit anti-CryPH antibodies (1: 1000), rabbit anti-GFP antibody (1: 500, Clontech, Mountain View, CA, USA) and mouse anti-Pys $25 \mathrm{mAb}$ (1: 20,000) at $37{ }^{\circ} \mathrm{C}$ for $1 \mathrm{~h}$, and thereafter with Alexa Fluor 488-goat anti-rabbit IgG antibody and Alexa Fluor 546-goat anti-mouse IgG antibody (Invitrogen) as secondary antibodies (1:500 dilution) at $37{ }^{\circ} \mathrm{C}$ for $30 \mathrm{~min}$, together with $1 \mu \mathrm{g} / \mathrm{mL}$ 4',6-diamidino-2-phenylindole (DAPI). After mounting in ProLong Gold antifade reagent (Invitrogen), samples were observed with an inverted fluorescence microscope (Axio observer z1, Carl Zeiss, Oberkochen, Germany), and images were taken using AxioVision software (Carl Zeiss).

\section{Immunoelectron microscopy (IEM)}

In vitro cultured $P y X N L$ zygotes/ookinetes were fixed for $30 \mathrm{~min}$ on ice in a mixture of $1 \%$ paraformaldehyde and $0.2 \%$ glutaraldehyde in $1 \times$ HEPES buffer ( $\mathrm{pH} 7.05$ ), then dehydrated and embedded in LR white resin (Polyscience Inc., Warrington, PA, USA). Ultrathin sections were blocked for $30 \mathrm{~min}$ in PBS containing $5 \%$ nonfat dry milk and $0.01 \%$ Tween 20 (PBS-MT), followed by overnight incubation with specific antibodies (1:50) in PBS-MT. After washing by PBS containing $10 \%$ BlockAce (DSPhama Co, Osaka, Japan) and 0.01\% Tween 20, samples were then incubated for $1 \mathrm{~h}$ in PBS-MT containing goat anti-rabbit IgG conjugated to $15 \mathrm{~nm}$ gold particles (1:20, BBI International, Minneapolis, MN, USA) [50]. The grids were stained with $2 \%$ uranyl acetate in $50 \%$ methanol and lead citrate. Samples were examined with a transmission electron microscope (JEM-1230; JEOL, Tokyo, Japan).

\section{Infectivity assay}

Parasite infected erythrocytes $\left(1 \times 10^{5}\right)$ or sporozoites $\left(1 \times 10^{4}\right)$ collected from salivary glands of CryPH-cont or $\triangle \mathrm{CryPH}$ infected mosquitoes, were inoculated into 4-week-old female ICR mice. Parasitaemias of infected mice were determined daily by Giemsa staining.

\section{Results}

Identification of pleckstrin homology domain-containing sexual-stage specific proteins conserved in Plasmodium spp.

To identify novel secreted or membrane-anchored proteins in sexual-stage parasites (gametes, zygotes, and 
ookinetes) in silico screening of the PlasmoDB databases was used to select 32 genes as candidates, as described in the methods section. This data set contains known surface/secreted proteins in gametocytes and ookinetes, such as P47 [51], two CPW-WPC proteins [44, 52], and four putative secreted ookinete proteins (PSOP) [36]; thus assuring that our criteria were reasonable. In this study, an uncharacterized protein containing 287 amino acid residues with an $\mathrm{N}$-terminal signal peptide (PY17X_0705200 in P. yoelii) was focused, whose transcription was apparently regulated by the sexual stage-specific transcription factors, AP2-G, AP2-G2, and AP2-O [53]. BLAST and synteny analyses [40] demonstrate that all Plasmodium spp. contain orthologous genes to PY17X_0705200, which are highly conserved in amino acid sequences (Fig. 1a); about $37 \%$ and $20 \%$ of amino acid residues are identical and strongly similar, respectively, among Plasmodium spp. The domain search algorithm SMART [54] and structure prediction algorithm (Phyre2) [55] revealed that PY17X_0705200 contains a pleckstrin homology domain ( $\mathrm{PH}$ domain), consisting of a $ß$-barrel of seven anti-parallel $ß$-sheets and an amphiphilic $\alpha$-helix (Fig. 1b). As it contains a PH domain and localizes to crystalloid bodies, demonstrated

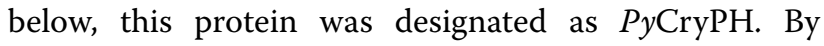
BLAST search using EupathDB (the Eukaryotic Pathogen Genomics Database) [56], predicted orthologous genes were found in the order Piroplasmida (Babesia and Theileria) and Cryptosporidium, with conserved features of an $\mathrm{N}$-terminal signal peptide and a $\mathrm{PH}$ domain. A possible homologue was also found in Toxoplasma, with relatively high amino acid sequence similarity despite the lack of an $\mathrm{N}$-terminal signal peptide. Recent strand-specific RNAseq analysis in Toxoplasma gondii raised the possibility that its translation starts from the internal methionine (at aa position 44 in TGME49_219160) that is immediately followed by a hydrophobic region that is robustly predicted to be a signal peptide sequence (SignalP; cbs.dtu. $\mathrm{dk} /$ services/SignalP/) [57]. Thus, the possibility should be considered that either the gene predictions in the Toxoplasma orthologues are in error or that translation is initiated at the downstream methionine. The alignment of amino acid sequences demonstrates that the sequence similarity is higher in the $\mathrm{PH}$ domain region and all four cysteine residues are conserved among $\mathrm{CryPH}$ orthologues (Additional file 1: Figure S2).

BLAST search and Phyre2 analysis revealed a gene adjacent to PY17X_0705200 in a tail-to-tail orientation which encodes a predicted paralogous protein containing a signal peptide and PH domain (PY17X_0705100, designated as PyCryPH-p; Fig. 1b) and 20\% identical amino acid residues (Fig. 1c). CryPH and CryPH-p orthologous genes are also adjacent in Babesia, Theileria, and Cryptosporidium. In addition, it was recently reported that a secretory protein with a $\mathrm{PH}$ domain is expressed in zygotes/ookinetes and localizes to the surface membrane (PY17X_0420000) [58]. The identity of amino acid residues in the PH domain of both proteins is about $25 \%$ and cysteine residues are conserved (Fig. 1d), although overall identity is low (17\%). The expression pattern of these three genes are similar; specifically, dominantly transcribed in female gametocytes and AP2-G2 dependent, which is also confirmed by the fact that all are selected by our screening criteria. Taken together, these pieces of evidence suggest that $\mathrm{CryPH}, \mathrm{CryPH}-\mathrm{p}$, and $\mathrm{PH}$ belong to a $\mathrm{PH}$ domain-containing protein family having sexual stage expression. Molecular phylogenetic analysis (Additional file 1: Figure S3) suggests that $\mathrm{CryPH}, \mathrm{CryPH}-\mathrm{p}$, and $\mathrm{PH}$ genes originated before genera within the phylum Apicomplexa diverged.

\section{CryPH is expressed in zygotes and ookinetes}

To raise specific rabbit antibodies against $\mathrm{CryPH}$ of $P$. yoelii, a recombinant protein corresponding to fulllength $\mathrm{CryPH}$ lacking the $\mathrm{N}$-terminal signal peptide (rCryPH) was produced by a wheat germ cell-free protein synthesis system (Fig. 2a). To evaluate the reactivity of anti-CryPH antibodies against native $\mathrm{CryPH}$ in the parasite lysate, Western blotting was performed using cultured zygotes/ookinetes of PyXNL parasites. Anti-CryPH antibodies recognize a protein in parasite lysates as a major band of approximately $35 \mathrm{kDa}$ under both non-reducing and reducing conditions, corresponding to a calculated molecular weight of

\footnotetext{
(See figure on next page.)

Fig. 1 Sequence alignment and predicted secondary structure of CryPH compared with its orthologues and PH domain family proteins. a Alignment of amino acid sequences of CryPH orthologues in Plasmodium. Amino acid sequences of Plasmodium CryPH (PY17X_0705200, PBANKA_0704900, PcyM_0507700, PVX_089075, PF3D7_0825700) are aligned using CLUSTALW program (https://npsa-prabi.ibcp.fr/cgi-bin/ npsa_automat.pl?page=npsa_clustalw.html). $\mathbf{b}$ Schematic representation of the secondary structure of PyCryPH, PyCryPH-p (PY17X_0705100), and PyPH (PY17X_0420000). Green and blue squares indicate the N-terminal signal peptide and PH domain. Blue arrows and purple square indicate B-sheets and a-helix. Numbers indicate amino acid positions from the first methionine. $\mathbf{c}$ Amino acid sequence comparison between PyCryPH and $\mathrm{PyCryPH}-\mathrm{p}$. Twenty percent of residues including all four cysteine residues are conserved between PyCryPH and PyCrePH-p. $\mathbf{d}$ Amino acid sequence alignment between $\mathrm{PH}$ domains of PyCryPH and PyPH. " "*" ".:", and "'.' indicate amino acid residues with full identity, strong similarity, and weak similarity, respectively
} 
a

P. yoelii 17XNL
P. berghei ANKA
P. cynomolgi M
P. vivax Sal-1
P. falcip. 3D7

P. yoelii 17XNL

P. berghei ANKA

P. cynomolgi $M$

P. vivax Sal-1

P. falcip. 3D7

(2)

K--VFVSTSF

20

20

30

30

40

50

60

60

70

80

।

90

I

100

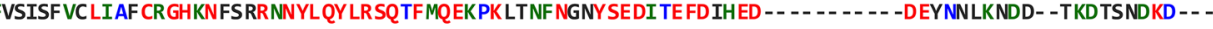

MK--IFVSISF VC LISF CK GHKNFSRR NNYL OYLRSOTF MOEK SK LTNF NGNY SEDITE FDIHED - - - - - - - - DEYNNFKNDKKKE KDTLNDKD - MR--VLSLLSAICLVST CR GHRN LF ARNNYLQYLRSQNF MQ EK PKYQKLNQYYSEDLNEFDNYED - - - - - - DELDAENLEAT -SKERVTQKSDTS MR--VLSLLSALCLVST CR GHRNLFARNNYLQYLRSQNF MQ EK PKFQKLNQNYSEDLNE FDNYED - - - - - - - - DELDAENVEAT -SKERVTQKSGTS MRNIIFLFCLI LF LVCF CQ GHKNYLKRDNYLQYLRSOTF LQER SKHKKFNRNY SEDINE FDEY EDEE TDNLDNKISDEI KNKKKENYLSQN INEQKNDS I *: : : : *:. *:**:* *:*********.*:**:.* ::* ****::***:**

**. : : : : :*.

$\begin{array}{rrrrrrrrrr}110 & 120 & 130 & 140 & 150 & 160 & 170 & 180 & 190 & 200 \\ \mid & \mid & \mid & \mid & \mid & \mid & \mid & \mid & \end{array}$ -MKENNKLEFKNLDKELN-TIEVNNP- -DSINIMGSGKE CSVNEK GE LDVS INSQDI FNLIKYMVEI TSNSIII IKDI KNSNVVKE LSYDHIKLPIET IEE -MKENNKLEFKNL EKELN-TNDVNNS- -DSINIMGSGKECSVNEK GE LDVS INSODI FNLIKYMVEI TSNS II IKDI KNSNVVKE LPYGNIKLPIET IEE SSSNENKLEFKNI EKELNNTGEVLHEE KDNL LLLGGGRECSVSDKGI LDVS LNSSDI FNLIKYTVEISSSGIL IRDTQNSNVKE ISFDTVKLPIET IEE SSSSENKLEFKNI EK EL NNMGEI LHEE KDNL LLMGGGRE CSVSDK GT LDVS LNSGDI FNLTKYTVEMSSSGIL IRDTQNSNVVKE IAFDTVKLPIET IEE NNNNEKKLTFKNIENEINSTDTFMDD- -SNVKSLGKTKECNVNEKGLLDVSLNSNDFFNMNKYNVEITSSNIII IKDKNNIKIIKE IPFEHIKLPITTIEE

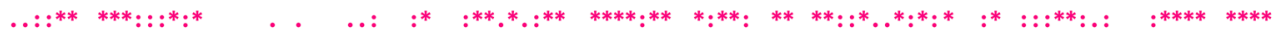

\begin{tabular}{rrrrrrrrrr}
210 & 220 & 230 & 240 & 250 & 260 & 270 & 280 & 290 & 300 \\
\hline & $\mid$ & $\mid$ & $\mid$ & $\mid$ & $\mid$ & $\mid$ & $\mid$ & $\mid$
\end{tabular}

P. yoelii 17XNL TRECWSIKFNKEKIIFCEKNKONRDNWVKDI LKALFCYNTNNL TI EN -NQKVYKQKSDI PKHSTVNERIQN - - LKET LTNDKNNFDKQKS-TKHNNNIVI

P. berghei ANKA TRECWSIKFNKEKIIFCEKNKQNRDKWVKDI LKALFCYNTNNL TIEN-NQNVYKQKSDIPKHSTVNERIQN -- LKETLTNDKNNFDKQKS-TKHNNNIVI

P. cynomolgi M TRECWKIRSHTETFLFCER SKEDRDRW IT NI LKAL FCYNTNNL TIDESVPTGLSS KVDI PKESTVDARIAAS- LKGE PNGSGDNSSHGR AKRK GNNNIT I

P. vivax Sal-1 TRECWKIRSHKETFLFCERSKEARDRWIT NMLKALFCYNTNNLTIDEGVQTGLSSKVDIPKESTVDARIAAS-LKDE PNGSGDNSSHGRAKRKGNNNIT I

P. falcip. $3 D 7$ TRECWYIKTTNDKIL LCDKEKEERDIWIT NI LKALFCYNTNNL IIVN-- -KEKKDTVSLPKESTVDKRINALKEKET IKSSDNNTSTNDN- -- KVNNIT I

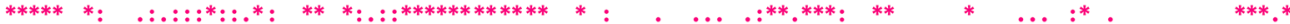

310

|

P. yoelii 17XNL SNLKNSNPNISLK

P. berghei ANKA SNLKSSNPNISLK

P. cynomolgi M SNLKNDKPEIVVN

P. vivax Sal-1 SNLKNDKPEIVVN

P. falcip. $3 D 7$ SNFSDHEPKIVFN

**. $\cdot * * *$ :

b

PyCryPH

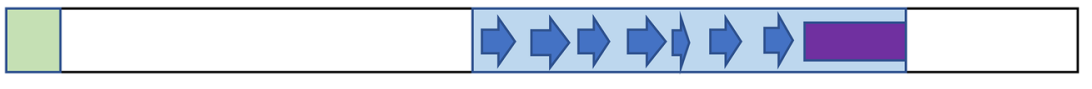

19

120

217

287

PyCryPH-p

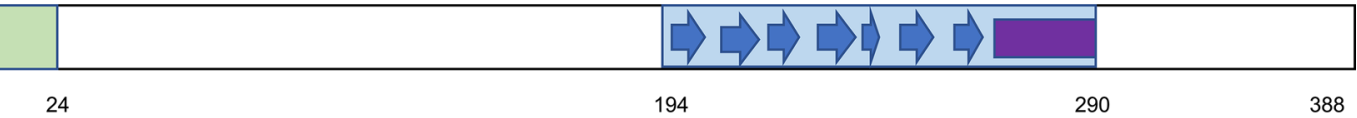

PyPH

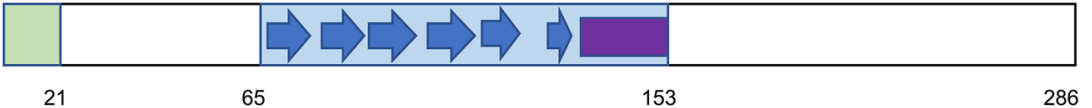

C

PY17X 0705200 PY17X-0705100

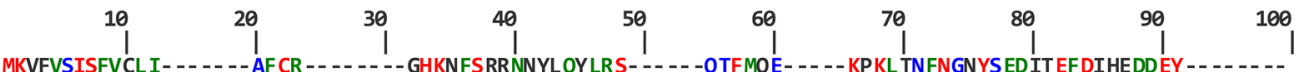
MKSSIKISYI LFVSCL LIRNGICQSF LPVSYATHKL YS FDKVSPNDIK SNVHNIVSNF IT SNLKVI KNKI EG YNSYYNKNNDEYDNLIQNEYDASL EDEV

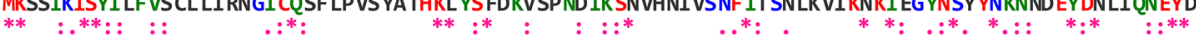

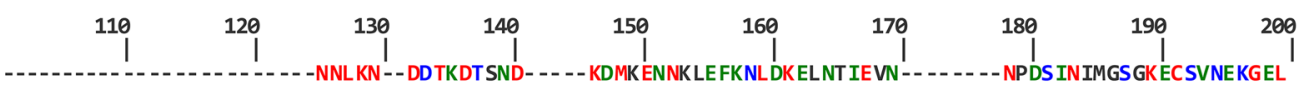

PY17X_0705200

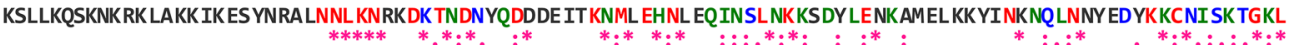

$\begin{array}{lllllllll}210 & 220 & 230 & 240 & 250 & 260 & 270 & 280 & 290\end{array}$ DVSINSODIF NL IKYMVE IT SNSI II KDIKNSNVVKEL SYDHIK LP IE TI EE TRECWS IK FNKE KI IF CE KN KONRDNWVKDIL KALF CYN - . - . - . - -

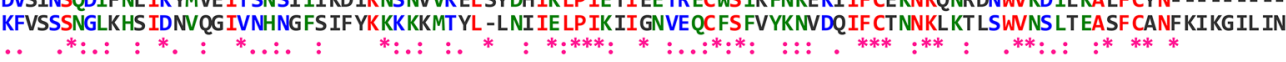

PY17X_0705100

PY17X 0705200

$\begin{array}{lllllll}310 & 320 & 330 & 340 & 350 & 360 & 370\end{array}$

TNNL TI ENNQKVYKQK SDIPKHSTVNER IQNL KE TL TNDKNN FDKQKS - - TKHNNNIVISNL KNSNPNISLK - - - . - -

LDNVDNESYKNI KK DN LLRINI KP DE KG TQVF VNGK KE NAKENGVINL NK IKKQAEDE EK IS KKEI LK EDDE SE QNEESEDNDDDNL

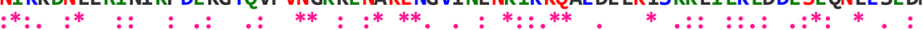

d

PY17X 0705200

10

VNEKGELDVS INSQDI FNLIKYMVEI TSNS II IKDI KNSNVVKE LSYDHIKLPIET IEET RECWSI KFN- -- KEKIIFCEKNKQNRDNWVKDIL KALF CYNT LKHLAGLVIDKSDKDAKL II EGSI ES NR LI FK LGNI KE -- - - KE INIKDI ILPIET LSH- -KCINIRQTNQN KDST VLCLANKVLRNF WT NS ITDAVL CKMT

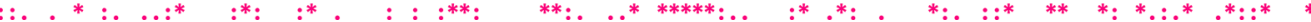




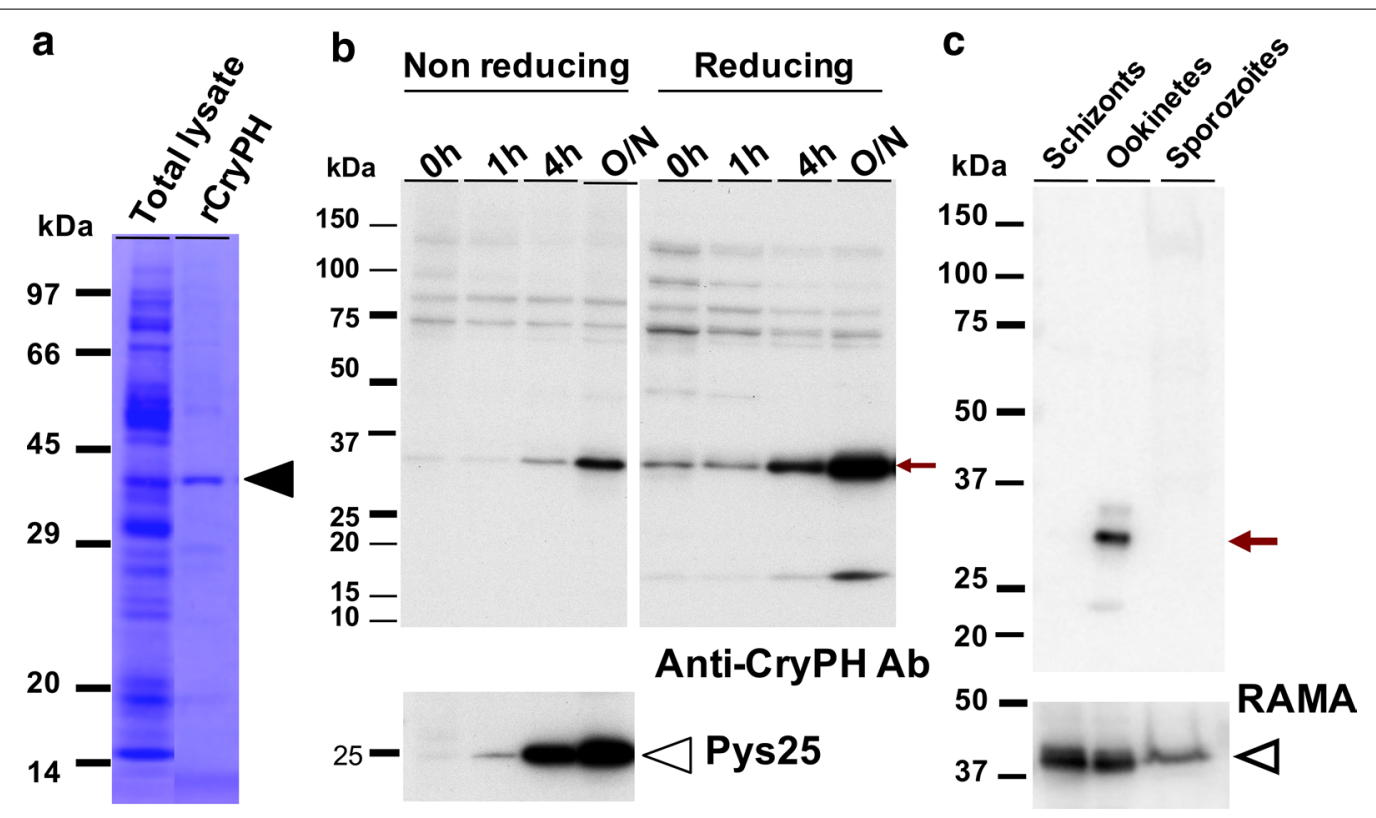

d Zygote Retort Ookinete

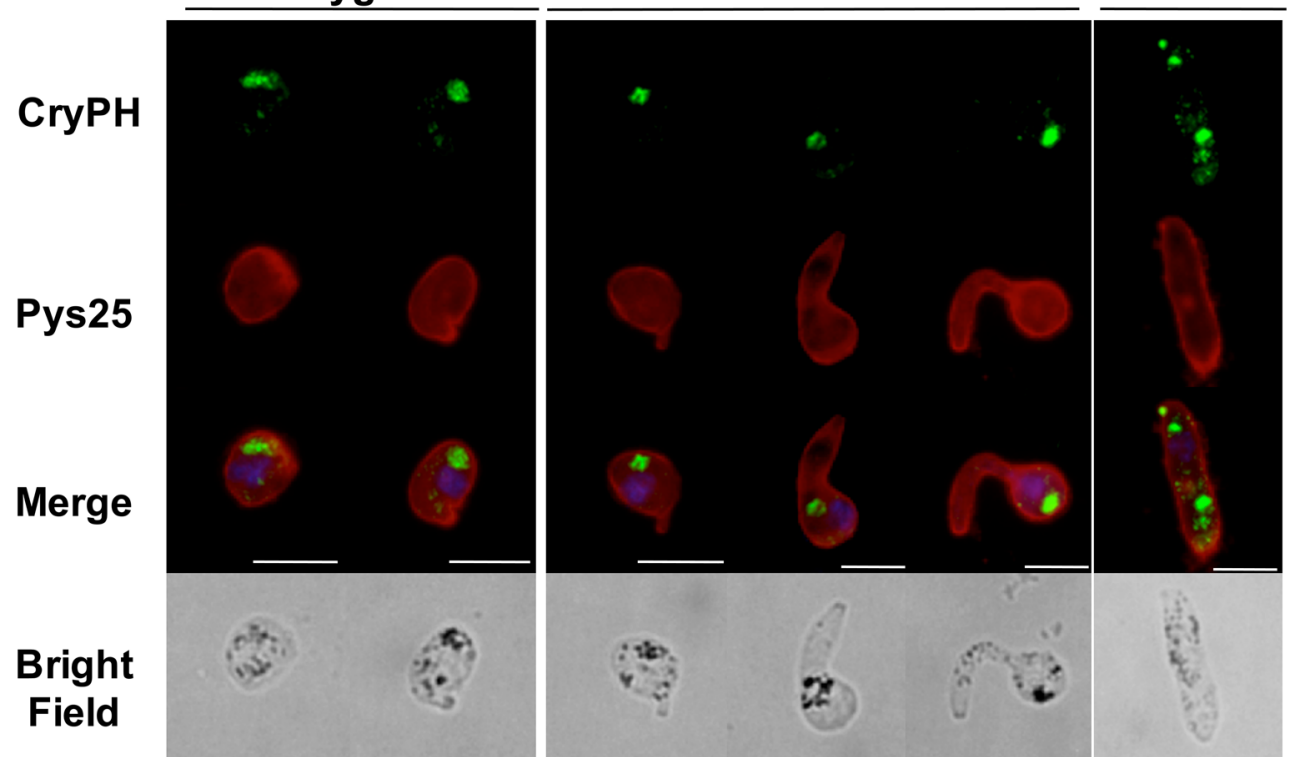

Fig. 2 PyCryPH is expressed in zygotes and ookinetes. a Expression of recombinant CryPH using the wheat germ cell-free protein expression system. Predicted size of the recombinant $\mathrm{CryPH}$ is indicated by an arrowhead. $\mathbf{b}$ Expression profile of CryPH examined by Western blotting analysis using extracts from in vitro ookinete culture. The same volumes of cultured parasites were taken at the times indicated above. Affinity purified anti-CryPH antibodies were used both under non-reducing (left panel) or reducing (right panel) conditions. The representative stages of parasites at each time point were as follows: 0 h, gametocytes and gametes; 1 h, zygotes; 4 h, retorts; and overnight incubation (O/N), mature ookinetes. The arrow indicates the bands corresponding to CryPH. The same filter was probed with anti-Pys 25 antibodies, a zygote/ookinete marker (Lower Panel). Open arrowhead indicates Pys25. c Expression comparison of CryPH in all infective stages. Protein lysates of schizonts, ookinetes, and oocyst-derived sporozoites $\left(1 \times 10^{5}\right)$ were separated by SDS-PAGE and CryPH expression, indicated by an arrow, was detected by Western blotting using anti-PyCryPH antibodies. Protein loading was assessed by re-probing with anti-RAMA antiserum (lower panel, arrow head). $\mathbf{d}$ Localization analysis of CryPH using immunofluorescence assay. CryPH was detected as clear circular spots in the parasite cytosol, and the signal intensity increased during ookinete development. Zygotes and ookinetes (retorts and mature ookinetes) cultured in vitro were fixed with acetone for immunofluorescence assays. CryPH signals were associated with malaria pigments. Merge, merged image of CryPH (green), Pys25 (red), and nuclei stained by DAPI (blue). Bars, $5 \mu \mathrm{m}$ 
CryPH (33.7 kDa; Fig. 2b, the lanes indicating overnight $(\mathrm{O} / \mathrm{N})$ culturing). The $\mathrm{CryPH}$ band intensity was faint before the start of parasite culturing $(0 \mathrm{~h})$ when gametocytes were predominant but increased with ookinete maturation. CryPH expression occurs almost simultaneously or slightly later than that of Pys 25 , a major surface molecule of zygotes and ookinetes. To determine $\mathrm{CryPH}$ protein profiling through the lifecycle, Western blotting was performed with all infective stage antigens; namely, schizonts (containing merozoites), ookinetes, and sporozoites derived from oocysts. $\mathrm{CryPH}$ expression was detected specifically in ookinetes (Fig. 2c).

To investigate $\mathrm{CryPH}$ localization in zygotes and ookinetes, IFA was performed using anti-CryPH antibodies. CryPH was initially detected as a diffuse or scattered pattern in the cytoplasm of zygotes. As parasites elongated to form mature ookinetes, the $\mathrm{CryPH}$ signal condensed as clear round shapes in the cytoplasm that overlapped with malaria pigments detected in the bright field images (Fig. 2d).

To further confirm CryPH localization, genetically modified $P y \mathrm{XNL}$ expressing GFP-tagged $\mathrm{CryPH}$ (CryPH-GFP) was generated (see Additional file 1: Figure S1a). Expression of GFP-tagged CryPH in ookinetes was confirmed by Western blotting using anti-CryPH antibodies (Fig. 3a, left and middle panels). IFA with anti-GFP antibodies confirmed the localization profile of $\mathrm{CryPH}$ in zygotes and ookinetes (Fig. 3b). In addition, the change in the number of round bodies at each developmental stage from zygote to ookinete was examined using CryPH-GFP parasites. One CryPHpositive round body was observed in $98 \%$ of zygotes. In the course of parasite development, the number of round bodies in the cytoplasm increased; specifically, $70 \%$ and $28 \%$ of mature ookinetes contained two and three round bodies in the cytoplasm of each parasite, respectively (Fig. 3c).

\section{CryPH localizes to crystalloid bodies in ookinetes}

IEM was performed to determine the precise subcellular localization of $\mathrm{CryPH}$ in zygotes and ookinetes. Gold particles showing the localization of $\mathrm{CryPH}$ were observed scattered in the vacuolar space of the cytoplasm in the female gamete or in the early stage zygote (Fig. 4a). In zygotes, small high-density particles, characteristic of crystalloid bodies, appeared but they were not well aligned and malaria pigments (arrowheads) surrounding crystalloid bodies were scarce (Fig. 4b). In developing/mature ookinetes, $\mathrm{CryPH}$ signals were observed to accumulate in crystalloid bodies surrounded by malaria pigments (Fig. 4c, d), demonstrating that $\mathrm{CryPH}$ is a novel crystalloid body protein.

\section{CryPH is dispensable for ookinete and sporozoite invasive ability}

To investigate the function of $\mathrm{CryPH}$ in zygotes and ookinetes, we generated PyCryPH-disrupted parasites $(\triangle \mathrm{CryPH})$ by homologous recombination to replace the endogenous $C r y P H$ locus with a human DHFR expression cassette as a selectable marker (see Additional file 1: Figure S1b). As a control, a human DHFR expression cassette was inserted at the same locus without changing $\mathrm{CryPH}$ expression (Additional file 1: Figure S1c, CryPH-cont). Two clones $(\triangle \mathrm{CryPH}$ cl1 and $\triangle \mathrm{CryPH} \mathrm{cl} 2$ ), derived from independent transfections, and a CryPH-cont clone were successfully isolated. Successful integration of the selectable marker into the $\mathrm{CryPH}$ locus was confirmed by genotyping PCR (Additional file 1: Figure S1d). The $\triangle \mathrm{CryPH}$ parasites at the intra-erythrocytic stage proliferated as efficiently as control parasites (CryPH-cont) by inoculation of parasite infected erythrocytes into mice, indicating that $\mathrm{CryPH}$ has no essential role in the blood-stage parasite development, as expected from its expression profile (Fig. 5a). After $\mathrm{O} / \mathrm{N}$ culturing of infected erythrocytes, $\triangle \mathrm{CryPH}$ developed into morphologically normal ookinetes (Fig. 5b). The absence of CryPH protein in $\triangle \mathrm{CryPH}$ ookinetes was confirmed by Western blotting (Fig. 3a, right panels) and IFA (Fig. 5b, lower panels). To evaluate the morphology of $\triangle \mathrm{CryPH}$ ookinetes in detail, electron microscopy was performed. Immunoelectron micrographs show that $\triangle \mathrm{CryPH}$ ookinetes have a normal apical structure, micronemes, and crystalloid bodies surrounded by malaria pigments (Fig. 5c). This finding demonstrates that $\mathrm{CryPH}$ is dispensable for ookinete maturation including the formation of crystalloid bodies. The ability of $\triangle \mathrm{CryPH}$ ookinetes to penetrate through the epithelial cells of mosquito midguts was unperturbed as the number of oocysts formed on the midgut wall at 10 days post-feeding was comparable in PyWT $(315 \pm 92 ; n=20)$ and $\Delta$ CryPH $(320 \pm 176$; $n=15$ ) parasite lines (Fig. $5 \mathrm{~d}$ ). The effect of $\mathrm{CryPH}$ disruption on sporozoite formation and maturation was then examined to assess the ability to invade salivary glands. The average number of sporozoites residing in the salivary glands per mosquito were 33,800 $(n=23)$ and $19,100(n=21)$ in PyWT and $\Delta \mathrm{CryPH}$, respectively, in experiment 1 ; and $6900(n=18)$ and $6700(n=15)$ in PyWT and $\triangle \mathrm{CryPH}$, respectively, in experiment 2. Sporozoite transmission ability to mice was examined by inoculation of 10,000 sporozoites collected from salivary glands of $\mathrm{CryPH}$-cont or $\triangle \mathrm{CryPH}$ infected mosquitoes. As shown in Fig. 5e, no significant 


\section{a}

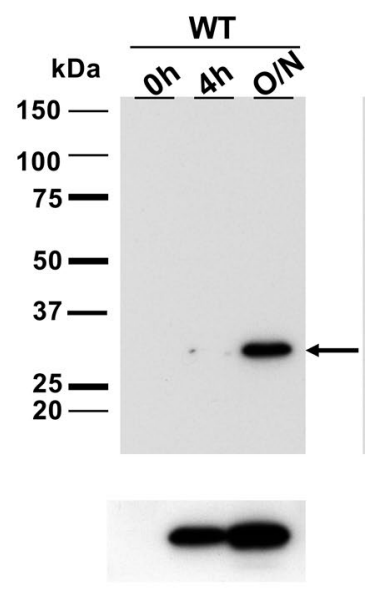

b

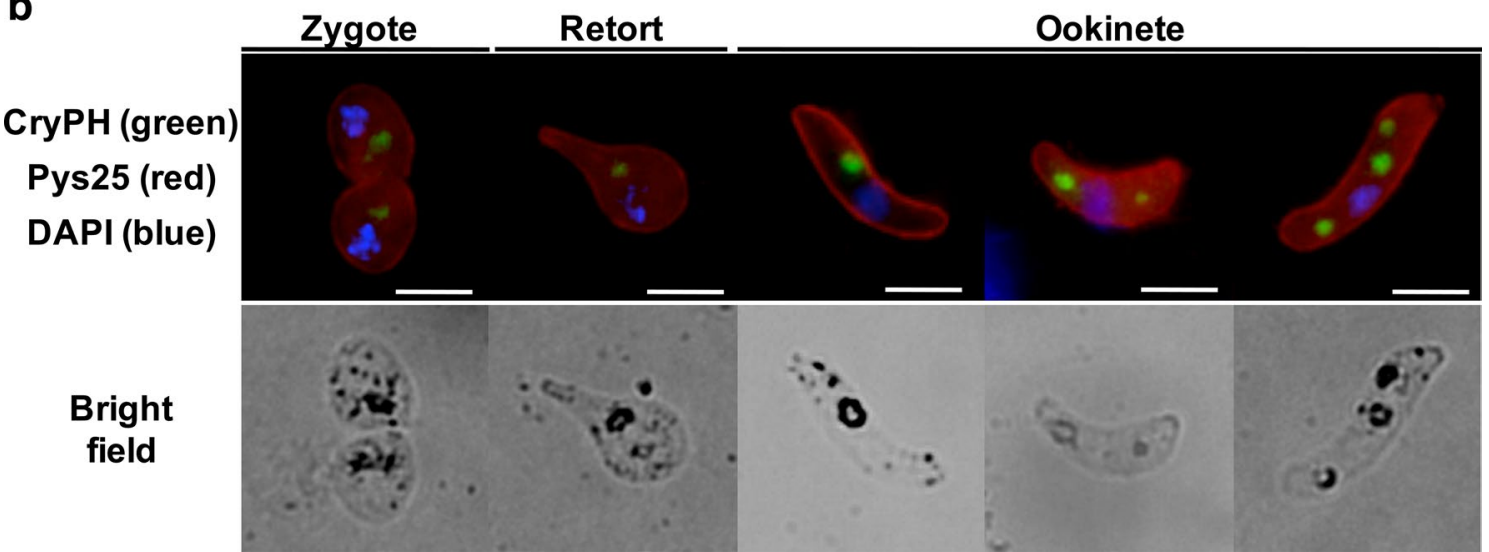

Fig. 3 Construction of CryPH-GFP expressing or CryPH gene depleted transgenic parasites. a Western blot analysis for confirmation of gene modification in isolated parasites. Wild-type (WT) or genetically modified (CryPH-GFP or $\triangle$ CryPH) PyXNL parasite lines cultured in vitro were collected at indicated time points. These parasites were analyzed by Western blot using anti-CryPH antibodies and anti-Pys 25 antibodies under non-reducing conditions. Left panels, a clear protein signal of the size comparable to that of native PyCryPH (indicated by a black arrow) was detected in WT ookinete lysate. Middle panels, one major band of about $60 \mathrm{kDa}$ corresponding to the predicted size of CryPH-GFP (indicated by a green arrow) was revealed in CryPH-GFP expressing transgenic ookinetes. Note that there was no signal of the size of native PyCryPH. Right panels, disappearance of $\mathrm{PyCryPH}$ signal in ookinetes with genetically disrupted PyCryPH showed that CryPH expression was completely depleted. In contrast, Pys 25 signal intensity was increased during culturing, suggesting that $\triangle C r y P H$ ookinetes formed normally (lower panel, indicated by an open arrow head). $\mathbf{b}$ Detection of CryPH-GFP by immunofluorescence analysis. Cultured CryPH-GFP parasites were stained using anti-GFP antibodies (green) and anti-Pys 25 antibodies (red). Nuclei were stained by DAPI (blue). Representative immunofluorescence assay images for parasites at each stage (upper panels) and corresponding bright field images (lower panels) are shown. Bars: 5 um. c The number of CryPH positive bodies was counted in a total of $300 \mathrm{CryPH}-\mathrm{GFP}$ expressing parasites. As the development of sexual stage parasites progressed from zygote, retort, to mature ookinete, the number of cell bodies expressing CryPH increased. Color codes in the column indicates the number of round bodies per parasite

difference was detected in parasitaemias of CryPH-cont or $\triangle \mathrm{CryPH}$ sporozoite inoculated mice, demonstrating that $\mathrm{CryPH}$ does not affect sporozoite infectivity. Taken together, these data suggest that $\mathrm{CryPH}$ is dispensable for the formation of ookinetes and sporozoites having complete invasive ability.

\section{Discussion}

Here, $\mathrm{CryPH}$ was identified as being expressed in zygotes and ookinetes, and localized to crystalloid bodies. Structure prediction demonstrated that $\mathrm{CryPH}$ orthologues in Plasmodium, Babesia, Theileria, and Cryptosporidium have a $\mathrm{PH}$ domain with an $\mathrm{N}$-terminal signal peptide. Recent comprehensive transcriptome and proteome analyses suggested that orthologues with the same structural feature exist in Toxoplasma. 

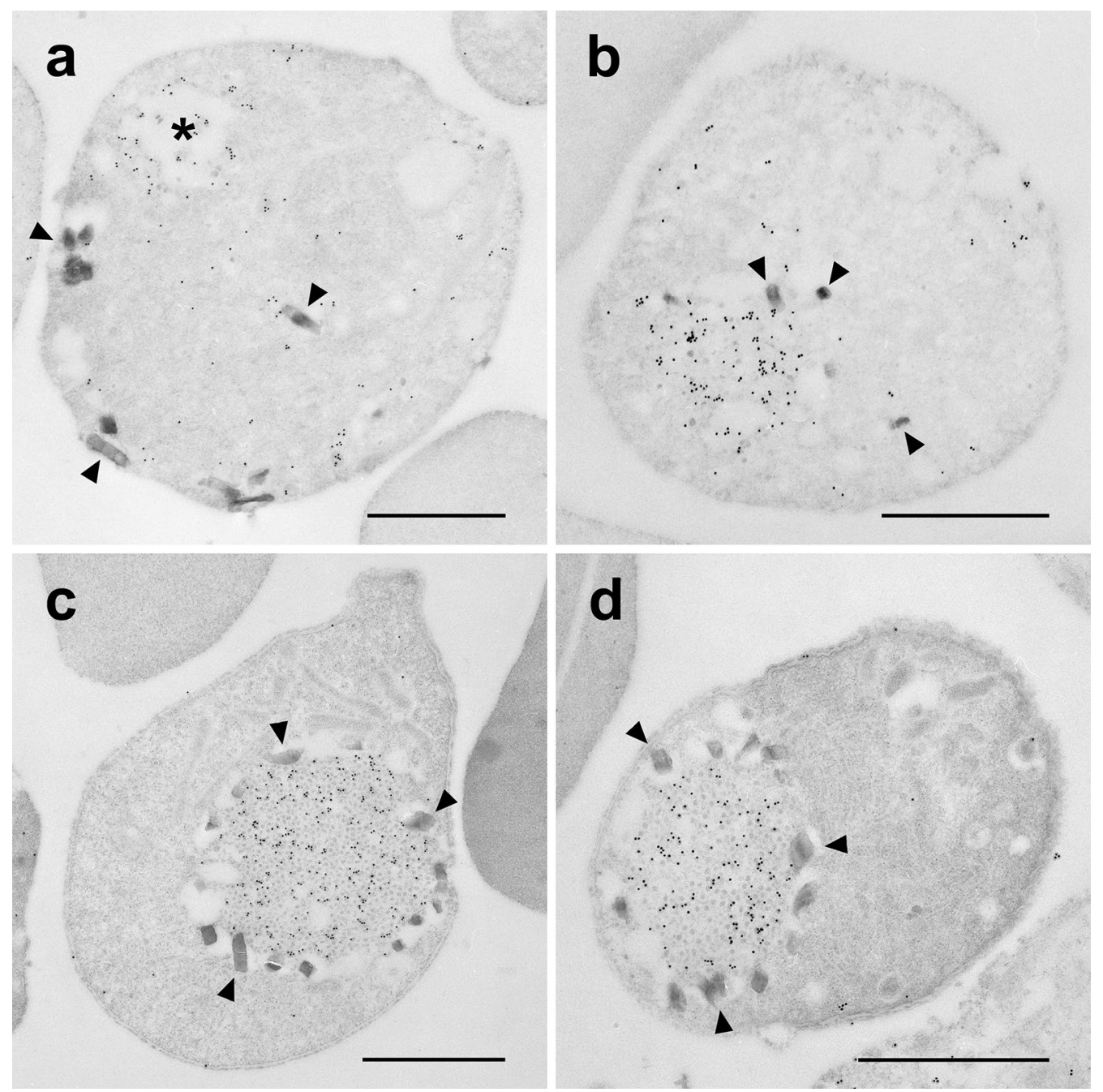

Fig. 4 Detailed localization analysis of CryPH by immunoelectron microscopy. a Gold particles indicating the localization of CryPH were observed diffusely throughout the cytoplasm whereas some particles accumulated around the vacuole ${ }^{*}$ ) in an early zygote. b Deposition of CryPH was observed when particle formation began in crystalloid bodies in zygotes. c, $\mathbf{d}$ In early retorts to mature ookinetes, CryPH localized to crystalloid bodies surrounded by malaria pigment. Arrowheads, malaria pigment. Bars: $1 \mu \mathrm{m}$

The in silico screening used here to select secreted or membrane anchored-proteins expressed predominantly in the sexual-stage parasites also included two more $\mathrm{PH}$ domain-containing proteins, CryPH-p, encoded by a gene adjacent to $\mathrm{CryPH}$, and $\mathrm{PH}$. The orthologues of the $\mathrm{PH}$ domain-containing proteins are widely conserved across the orders in the phylum Apicomplexa, including Plasmodium, Babesia, Theileria, Cryptosporidium, and Toxoplasma, suggesting that they may have important roles common to these parasites. The PH domain, found in a wide range of proteins, binds phosphatidylinositol lipids and proteins such as the subunits of heterotrimeric G proteins and protein kinase C [59-61]. Through these interactions, the $\mathrm{PH}$ domain recruits proteins to different membranes, thereby targeting them to the proper cellular compartments [62], or interacts with the appropriate components of the signal transduction pathway [63-65]. IEM observation revealed that $\mathrm{CryPH}$ starts accumulating before the typical crystalloid body structure appears (Fig. 4b), raising the possibility that $\mathrm{CryPH}$ might be involved in crystalloid body formation by transporting proteins to the vesicles of crystalloid bodies in Plasmodium. Since CryPH orthologues are found in Babesia, Theileria, and possibly in Toxoplasma, in which crystalloid bodies have not been reported, another possibility is that $\mathrm{CryPH}$ may have more generic roles such as protein trafficking to target organelles. 

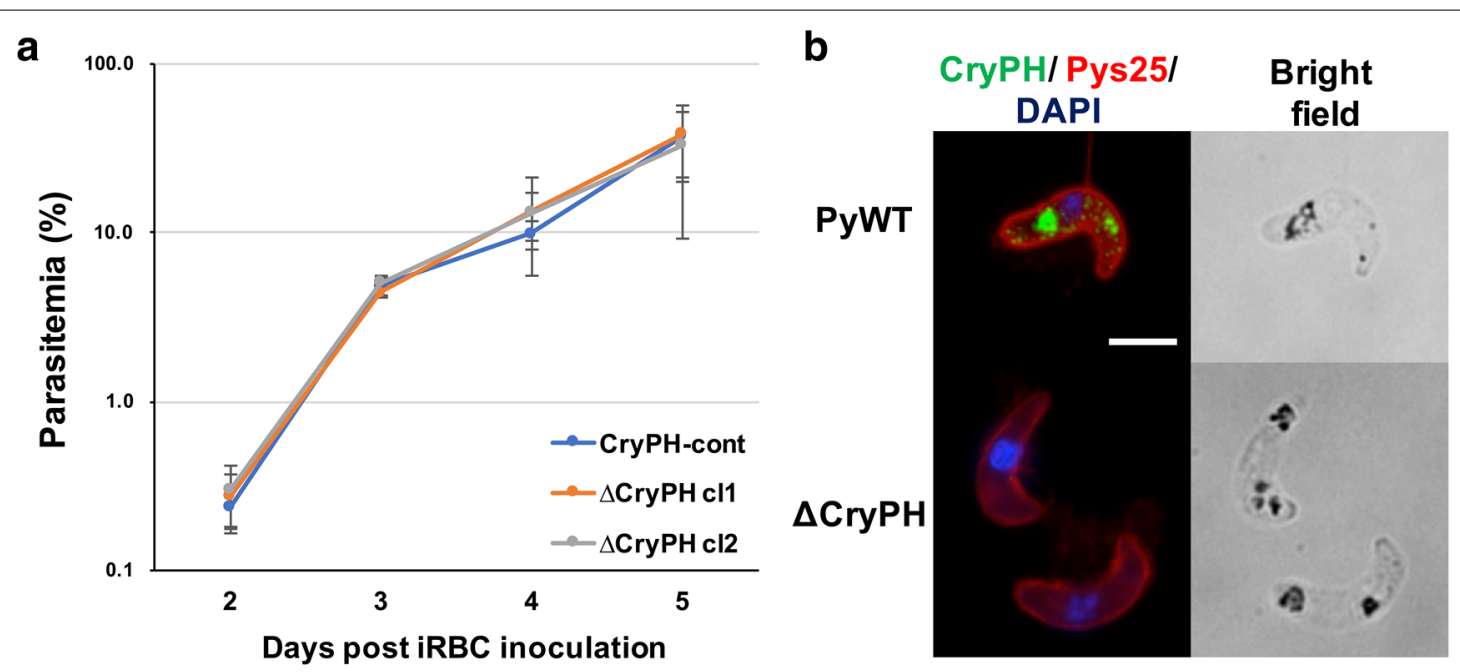

C

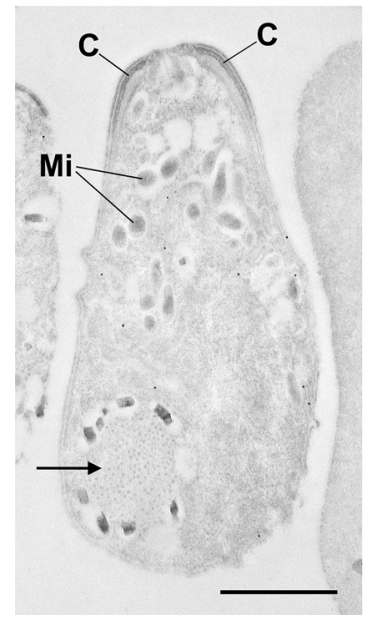

d

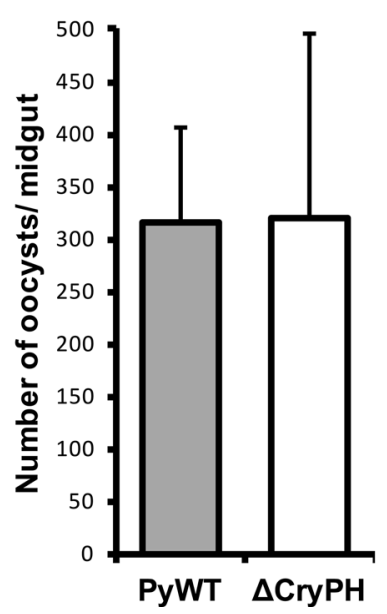

e

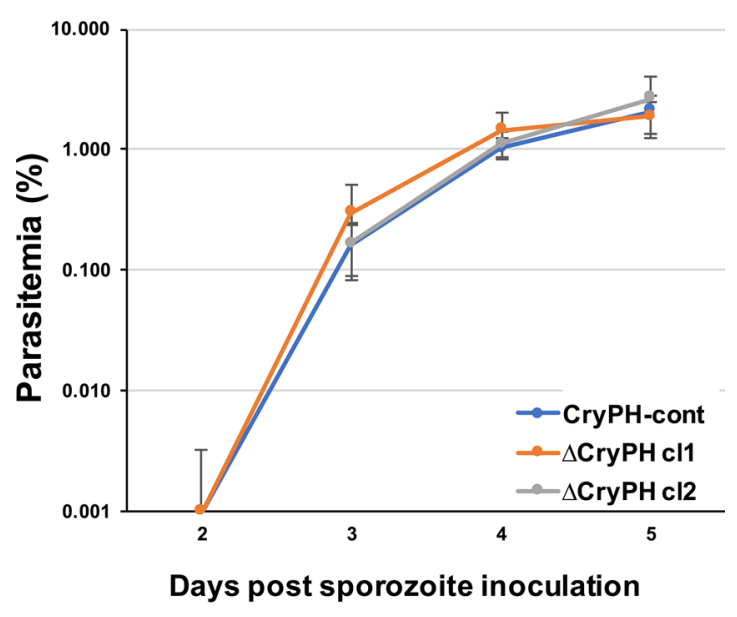

Fig. $5 \mathrm{CryPH}$ is dispensable for ookinete and sporozoite formation and their infectivity. a Erythrocytes $\left(1 \times 10^{5}\right)$ infected with $\mathrm{CryPH}$-cont or $\Delta \mathrm{CryPH}$ ( $\mathrm{Cl}$ and $\mathrm{Cl}$ ) parasites were inoculated intravenously into 4-week-old female ICR mice pretreated with phenylhydrazine. Parasitemias were examined daily by Giemsa staining. Parasitemia data from five mice are presented as the mean \pm standard deviation. $\mathbf{b}$ Immunofluorescence assay of PyWT and $\triangle \mathrm{CryPH}$ using anti-CryPH antibodies (green) and anti-Pys 25 antibodies (red). Nuclei were stained by DAPI (blue). Bar: $5 \mu \mathrm{m}$. c Immunoelectron microscopy image of $\triangle \mathrm{CryPH}$ showing normal ookinete apical structure. A crystalloid body (arrow) with a normal structure surrounded by malaria pigments is shown, but gold particles indicating CryPH localization were not observed. C: electron dense collar. Mi: microneme. Bar: $1 \mu \mathrm{m}$. $\mathbf{d}$ The number of oocysts formed on the mosquito midgut. Mosquitoes (PyWT, $n=20, \Delta \mathrm{CryPH}, n=15$ ) were dissected 10 days after they were fed with infected blood. e Sporozoites $\left(1 \times 10^{4}\right)$ collected from salivary glands of $\mathrm{CryPH}$-cont or $\Delta \mathrm{CryPH}(\mathrm{cl} 1$ and $\mathrm{Cl} 2)$ infected mosquitoes were inoculated intravenously into female ICR mice. Parasitemias were examined daily by Giemsa staining. Parasitemia data from five mice are presented as the mean \pm standard deviation. No significant difference was observed in the infectivity between $C r y P H$-cont and $\Delta C$ ryPH sporozoites

The crystalloid body is a unique honeycomb-like structure observed in the cytoplasm of Plasmodium ookinetes and young oocysts, which has been suggested as a reservoir of proteins required for sporozoite formation. It has been demonstrated that LAP/CCp family proteins with characteristic LCCL domains are localized to crystalloid bodies in P. berghei and P. falciparum [26, 66]. Disruption of the LAP family proteins in $P$. berghei demonstrated that they are required for crystalloid body formation and subsequent sporozoite maturation inside oocysts, strongly supporting the hypothesis that crystalloid bodies contain proteins and/or nutrients required for parasite transmission (summarized in Table 1) [14, $67,68]$. However, the molecular mechanisms of crystalloid body formation and mode of action of LAP family proteins remain to be elucidated. The fact that all crystalloid body proteins, including $\mathrm{CryPH}$, contain $\mathrm{N}$-terminal signal peptides suggests that protein trafficking to 
the crystalloid bodies is dependent on the endoplasmic reticulum. By using targeted $\mathrm{CryPH}$ gene-disruption it was revealed that, unlike LAP family proteins, $\mathrm{CryPH}$ is dispensable for parasite transmission via mosquitoes, that includes crystalloid body formation in ookinetes and sporozoite formation with the ability to invade salivary glands. Despite this, given that $\mathrm{CryPH}$ contains a $\mathrm{PH}$ domain in the secondary structure, and accumulates in vesicles prior to the typical crystalloid body formation implies that $\mathrm{CryPH}$ is involved in crystalloid formation. CryPH-p may compensate the role of $\mathrm{CryPH}$ in disrupted parasites, since their expression profile is similar. Localization analysis of CryPH-p and generation of double-knockout parasites will reveal their contribution for crystalloid formation. Future identification of proteins/ molecules interacting with the $\mathrm{PH}$ domain of $\mathrm{CryPH}$, for example by BioID technology, will likely provide clues to elucidate the biology of crystalloid body formation.

\section{Conclusions}

In this study $\mathrm{CryPH}$ was described as a $\mathrm{PH}$ domaincontaining protein, which specifically localized to crystalloid bodies in ookinetes of $P$. yoelii. This protein does not share the multi-domain architectures characteristic of the LAP/CCp family proteins which are also localized in crystalloid bodies. CryPH is dispensable for erythrocytic- and mosquito-stage parasite development, as demonstrated by the observation that genetically modified CryPH-deficient $P$. yoelii normally developed into ookinetes, oocysts, sporozoites as well as intra-erythrocyticstage parasites.

\section{Additional file}

Additional file 1: Figure S1. Construction of transgenic parasites with $\mathrm{CryPH}$ gene modifications. (a) Schematic representation of the generation of GFP-tagged CryPH expressing parasites. The native PyCryPH gene locus was replaced with a coding sequence of $\mathrm{CryPH}$ tagged by GFP at the C-terminal by double-crossover homologous recombination. The vector contains two homologous regions, the coding region of the C-terminal of $\mathrm{CryPH}$ (striped orange box, $\mathrm{CryPH}-\mathrm{C}$ ), which is connected in frame to GFP coding sequence (green box, GFP), and the 3'-UTR of CryPH (grid orange box, $\mathrm{CryPH}-3^{\prime}$ ). For selection of DNA integrated parasites, human DHFR coding sequence (dotted green box, hDHFR) is inserted between them. The resulting integrated locus is shown in the bottom panel. (b) Schematic representation of the targeted gene disruption of $\mathrm{CryPH}$. The CryPH-coding region in the genome is replaced with the human DHFR expression cassette (dotted green box) by homologous recombination at the sites corresponding to the $5^{\prime}$ - and $3^{\prime}-$ UTR of $\mathrm{CryPH}$ (grid orange box). (c) Generation of CryPH-control (CryPH-cont) parasites. By homologous recombination, human DHFR expression cassette (dotted green box) is inserted next to the CryPH gene with the transgenic vector containing two homologous recombination sites corresponding to CryPH-C and 3'-UTR of CryPH (striped and grid orange boxes). Parasites with integrated DNA (bottom panel) were selected by drug treatment. (d) PCR genotyping of transgenic parasites. Correct DNA insertion into the PyCryPH locus of $\triangle \mathrm{CryPH}(\mathrm{Cl} 1$ and $\mathrm{cl} 2)$ and $\mathrm{CryPH}$-cont transgenic parasites was confirmed by PCR using specific primer sets. The amplicons were diagnostic for: lane 1, integrated form; lane 2, episomal form; lane 3, wild-type. The expected sizes of the amplified fragments (lanes 1-3) were 1,000 bp, 1,235 bp, and 1,030 bp, respectively. Episomal form was not detected in any clones. Figure S2. Alignment of amino acid sequences of $\mathrm{CryPH}$ orthologues in apicomplexan parasites. Amino acid sequences of CryPH orthologues in Plasmodium yoelii (PY17X_0705200), Toxoplasma gondii (TGME49_219160), Theileria equi (BEWA_008110), Babesia microti (BMR1_02g03021), and Cryptosporidium meleagridis (CmeUKMEL1_06995) are aligned using CLUSTALW algorithm (https://npsa-prabi.ibcp.fr/cgi-bin/ npsa_automat.pl?.page=npsa_clustalw.html). Underbars indicate the signal peptide of each sequence. Strand-specific RNA-seq data suggested that translation of predicted Toxoplasma CryPH may start from the internal methionine (marked in orange). Approximately $3 \%$ of residues including all cysteine residues are conserved among $\mathrm{CryPH}$ orthologues. Similarity is higher in the $\mathrm{PH}$ domain predicted by the secondary structure of $\mathrm{PyCryPH}$, indicated by a box. Figure S3. Molecular phylogenetic analysis by the Maximum Likelihood method. The evolutionary history was inferred using the Maximum Likelihood method [69]. The initial tree for the heuristic search was obtained automatically by applying Neighbor-Join and BioNJ algorithms to a matrix of pairwise distances estimated using a JTT model, and then selecting the topology with superior log likelihood value. All positions containing gaps and missing data were eliminated. Evolutional analyses were conducted in MEGA7 [70].

\section{Abbreviations}

CryPH: crystalloid body specific protein containing PH domain; DAPI: 4',6-diamidino-2-phenylindole; DHFR: dihydrofolate reductase gene; HRP: horseradish peroxidase; LAP: LCCL lectin adhesive-like proteins; PV: parasitophorous vacuole; SDS-PAGE: sodium dodecyl sulphate polyacrylamide gel electrophoresis.

\section{Authors' contributions}

$\mathrm{RJ}$ and TI designed the experiments. RJ and MTa produced the recombinant protein and antibodies. RJ, $\mathrm{HO}$ and TI produced transgenic parasites. RJ and NK prepared the cultured ookinetes. RJ, NK, MTa and HO performed the Westernblotting and immunofluorescence assay. AT and MTo performed the immunoelectron microscopy. RJ and TI dissected mosquitoes and counted sporozoite numbers. RJ, MTo and TI were major contributors in writing the manuscript. $J S$ and TT supervised the research and critically reviewed the manuscript. All authors read and approved the final manuscript.

\section{Author details}

${ }^{1}$ Division of Molecular Parasitology, Proteo-Science Center, Ehime University, Toon, Ehime 791-0295, Japan. ${ }^{2}$ Mahidol Vivax Research Unit, Faculty of Tropical Medicine, Mahidol University, Bangkok 10400, Thailand. ${ }^{3}$ Department of Pathobiology, Faculty of Science, Mahidol University, Bangkok 10400, Thailand. ${ }^{4}$ Department of Biology, Faculty of Science, Burapha University, Chonburi 20131, Thailand. ${ }^{5}$ Division of Medical Zoology, Faculty of Medicine, Tottori University, Yonago, Tottori 683-8503, Japan. ${ }^{6}$ Division of Malaria Research, Proteo-Science Center, Ehime University, Matsuyama, Ehime 790-8577, Japan.

\section{Acknowledgements}

We thank Masachika Shudo (Advanced Research Support Center, Ehime University) for technical assistance with electron microscopy.

\section{Competing interests}

The authors declare that they have no competing interests.

\section{Availability of data and materials}

The datasets supporting the conclusions of this article are included within the article and its additional files.

\section{Consent for publication}

Not applicable.

Ethics approval and consent to participate

Not applicable. 


\section{Funding}

This study was partially supported by the Ministry of Education, Culture, Sports, Science and Technology of Japan, KAKENHI (24390101, 24590506, 26305010).

\section{Publisher's Note}

Springer Nature remains neutral with regard to jurisdictional claims in published maps and institutional affiliations.

Received: 20 October 2018 Accepted: 6 December 2018

Published online: 13 December 2018

\section{References}

1. Sinden RE. The cell biology of malaria infection of mosquito: advances and opportunities. Cell Microbiol. 2015;17:451-66.

2. Pimenta PF, Touray M, Miller L. The journey of malaria sporozoites in the mosquito salivary gland. J Eukaryot Microbiol. 1994;41:608-24.

3. Hillyer JF, Barreau C, Vernick KD. Efficiency of salivary gland invasion by malaria sporozoites is controlled by rapid sporozoite destruction in the mosquito haemocoel. Int J Parasitol. 2007;37:673-81.

4. Torii M, Nakamura K, Sieber KP, Miller LH, Aikawa M. Penetration of the mosquito (Aedes aegypti) midgut wall by the ookinetes of Plasmodium gallinaceum. J Protozool. 1992;39:449-54.

5. Baton LA, Ranford-Cartwright LC. Spreading the seeds of million-murdering death: metamorphoses of malaria in the mosquito. Trends Parasitol. 2005;21:573-80.

6. Blackman MJ, Bannister LH. Apical organelles of Apicomplexa: biology and isolation by subcellular fractionation. Mol Biochem Parasitol. 2001:117:11-25.

7. Sinden RE. A proteomic analysis of malaria biology: integration of old literature and new technologies. Int J Parasitol. 2004;34:1441-50.

8. Lal K, Prieto J, Bromley E, Sanderson S, Yates J, Wastling J, et al. Characterization of Plasmodium invasive organelles; an ookinete microneme proteome. Proteomics. 2009;9:1142-51.

9. Garnham PC, Bird RG, Baker JR. Electron microscope studies of motile stages of malaria parasites. III. The ookinetes of Haemamoeba and Plasmodium. Trans R Soc Trop Med Hyg. 1962;56:116-20.

10. Garnham PC, Bird RG, Baker JR, Desser SS, El-Nahal HM. Electron microscope studies on motile stages of malaria parasites. VI. The ookinete of Plasmodium berghei yoelii and its transformation into the early oocyst. Trans R Soc Trop Med Hyg. 1969;63:187-94.

11. Trefiak WD, Desser SS. Crystalloid inclusions in species of Leucocytozoon, Parahaemoproteus, and Plasmodium. J Protozool. 1973;20:73-80.

12. Lemgruber $L$, Lupetti $P$. Crystalloid body, refractile body and virus-like particles in Apicomplexa: what is in there? Parasitology. 2012;139:285-93.

13. Meis JF, Ponnudurai T. Ultrastructural studies on the interaction of Plasmodium falciparum ookinetes with the midgut epithelium of Anopheles stephensi mosquitoes. Parasitol Res. 1987;73:500-6.

14. Carter V, Shimizu S, Arai M, Dessens JT. PbSR is synthesized in macrogametocytes and involved in formation of the malaria crystalloids. Mol Microbiol. 2008;68:1560-9.

15. Wong TC, Desser SS. Fine structure of oocyst transformation and the sporozoites of Leucocytozoon dubreuili. J Protozool. 1976;23:115-26.

16. Brockley Paterson W, Desser SS. The polar ring complex in ookinetes of Leucocytozoon simondi (Apicomplexa: Haemosporina) and evidence for a conoid in haemosporidian ookinetes. Eur J Protistol. 1989;24:244-51.

17. Lowichik A, Lanners HN, Lowrie RC Jr, Meiners NE. Gametogenesis and sporogony of Hepatozoon mocassini (Apicomplexa: Adeleina: Hepatozoidae) in an experimental mosquito host, Aedes aegypti. J Eukaryot Microbiol. 1993;40:287-97.

18. Boulard Y, Paperna I, Petit G, Landau I. Ultrastructure of developmental stages of Hemolivia stellata (Apicomplexa: Haemogregarinidae) in the cane toad Bufo marinus and in its vector tick Amblyomma rotondatum. Parasitol Res. 2001;87:598-604.

19. Roberts WL, Mahrt JL, Hammond DM. The fine structure of the sporozoites of Isospora canis. Z Parasitenkd. 1972:40:183-94.
20. Mehlhorn H, Markus MB. Electron microscopy of stages of Isospora felis of the cat in the mesenteric lymph node of the mouse. Z Parasitenkd. 1976:51:15-24.

21. Lindsay DS, Dubey JP, Toivio-Kinnucan MA, Michiels JF, Blagburn BL. Examination of extraintestinal tissue cysts of Isospora belli. J Parasitol. 1997;83:620-5.

22. Speer CA, Dubey JP. Ultrastructure of sporozoites and zoites of Hammondia heydorni. J Protozool. 1989;36:488-93.

23. Lumb R, Smith K, O'Donoghue PJ, Lanser JA. Ultrastructure of the attachment of Cryptosporidium sporozoites to tissue culture cells. Parasitol Res. 1988;74:531-6.

24. Tetley L, Brown SM, McDonald V, Coombs GH. Ultrastructural analysis of the sporozoite of Cryptosporidium parvum. Microbiology. 1998;144(Pt 12):3249-55.

25. Valigurova A, Paskerova GG, Diakin A, Kovacikova M, Simdyanov TG. Protococcidian Eleutheroschizon duboscai, an unusual Apicomplexan interconnecting Gregarines and Cryptosporidia. PLoS ONE. 2015;10:e0125063.

26. Saeed S, Carter V, Tremp AZ, Dessens JT. Plasmodium berghei crystalloids contain multiple LCCL proteins. Mol Biochem Parasitol. 2010;170:49-53.

27. Saeed S, Carter V, Tremp AZ, Dessens JT. Translational repression controls temporal expression of the Plasmodium berghei LCCL protein complex. Mol Biochem Parasitol. 2013;189:38-42.

28. Lasonder E, Ishihama Y, Andersen JS, Vermunt AM, Pain A, Sauerwein RW, et al. Analysis of the Plasmodium falciparum proteome by high-accuracy mass spectrometry. Nature. 2002;419:537-42.

29. Pradel G, Hayton K, Aravind L, lyer LM, Abrahamsen MS, Bonawitz A, et al. A multidomain adhesion protein family expressed in Plasmodium falciparum is essential for transmission to the mosquito. J Exp Med. 2004;199:1533-44.

30. Pradel G, Wagner C, Mejia C, Templeton TJ. Plasmodium falciparum: codependent expression and co-localization of the PfCCp multi-adhesion domain proteins. Exp Parasitol. 2006;112:263-8.

31. Scholz SM, Simon N, Lavazec C, Dude MA, Templeton TJ, Pradel G. PfCCp proteins of Plasmodium falciparum: gametocyte-specific expression and role in complement-mediated inhibition of exflagellation. Int J Parasitol. 2008:38:327-40.

32. Simon N, Scholz SM, Moreira CK, Templeton TJ, Kuehn A, Dude MA, et al. Sexual stage adhesion proteins form multi-protein complexes in the malaria parasite Plasmodium falciparum. J Biol Chem. 2009;284:14537-46.

33. Claudianos C, Dessens JT, Trueman HE, Arai M, Mendoza J, Butcher GA, et al. A malaria scavenger receptor-like protein essential for parasite development. Mol Microbiol. 2002;45:1473-84.

34. Trueman HE, Raine JD, Florens L, Dessens JT, Mendoza J, Johnson J, et al. Functional characterization of an LCCL-lectin domain containing protein family in Plasmodium berghei. J Parasitol. 2004;90:1062-71.

35. Raine JD, Ecker A, Mendoza J, Tewari R, Stanway RR, Sinden RE. Female inheritance of malarial lap genes is essential for mosquito transmission. PLoS Pathog. 2007;3:e30.

36. Ecker A, Bushell ES, Tewari R, Sinden RE. Reverse genetics screen identifies six proteins important for malaria development in the mosquito. Mol Microbiol. 2008;70:209-20.

37. Lavazec C, Moreira CK, Mair GR, Waters AP, Janse CJ, Templeton TJ. Analysis of mutant Plasmodium berghei parasites lacking expression of multiple PbCCp genes. Mol Biochem Parasitol. 2009;163:1-7.

38. Le Roch KG, Zhou Y, Blair PL, Grainger M, Moch JK, Haynes JD, et al. Discovery of gene function by expression profiling of the malaria parasite life cycle. Science. 2003;301:1503-8.

39. Yuda M, Iwanaga S, Kaneko I, Kato T. Global transcriptional repression: an initial and essential step for Plasmodium sexual development. Proc Natl Acad Sci USA. 2015:112:12824-9.

40. Aurrecoechea C, Brestelli J, Brunk BP, Dommer J, Fischer S, Gajria B, et al. PlasmoDB: a functional genomic database for malaria parasites. Nucleic Acids Res. 2009;37:D539-43.

41. Tsuboi T, Takeo S, Iriko H, Jin L, Tsuchimochi M, Matsuda S, et al. Wheat germ cell-free system-based production of malaria proteins for discovery of novel vaccine candidates. Infect Immun. 2008;76:1702-8.

42. Tsuboi T, Takeo S, Arumugam TU, Otsuki H, Torii M. The wheat germ cell-free protein synthesis system: a key tool for novel malaria vaccine candidate discovery. Acta Trop. 2010;114:171-6. 
43. Otsuki H, Kaneko O, Thongkukiatkul A, Tachibana M, Iriko H, Takeo S, et al. Single amino acid substitution in Plasmodium yoelii erythrocyte ligand determines its localization and controls parasite virulence. Proc Natl Acad Sci USA. 2009;106:7167-72.

44. Kangwanrangsan N, Tachibana M, Jenwithisuk R, Tsuboi T, Riengrojpitak $\mathrm{S}$, Torii M, et al. A member of the CPW-WPC protein family is expressed in and localized to the surface of developing ookinetes. Malar J. 2013;12:129.

45. Janse CJ, Ramesar J, Waters AP. High-efficiency transfection and drug selection of genetically transformed blood stages of the rodent malaria parasite Plasmodium berghei. Nat Protoc. 2006;1:346-56.

46. Jongco AM, Ting LM, Thathy V, Mota MM, Kim K. Improved transfection and new selectable markers for the rodent malaria parasite Plasmodium yoelii. Mol Biochem Parasitol. 2006;146:242-50.

47. Rodriguez MC, Margos G, Compton H, Ku M, Lanz H, Rodriguez MH, et al. Plasmodium berghei: routine production of pure gametocytes, extracellular gametes, zygotes, and ookinetes. Exp Parasitol. 2002;101:73-6.

48. Tsuboi T, Cao YM, Hitsumoto Y, Yanagi T, Kanbara H, Torii M. Two antigens on zygotes and ookinetes of Plasmodium yoelii and Plasmodium berghei that are distinct targets of transmission-blocking immunity. Infect Immun. 1997;65:2260-4.

49. Ishino T, Murata E, Tokunaga N, Baba M, Tachibana M, Thongkukiatkul A, et al. Rhoptry neck protein 2 expressed in Plasmodium sporozoites plays a crucial role during invasion of mosquito salivary glands. Cell Microbiol. 2018;20:e12964.

50. Tachibana M, Ishino T, Takashima E, Tsuboi T, Torii M. A male gametocyte osmiophilic body and microgamete surface protein of the rodent malaria parasite Plasmodium yoelii (PyMiGS) plays a critical role in male osmiophilic body formation and exflagellation. Cell Microbiol. 2018;20:e12821.

51. Ukegbu CV, Giorgalli M, Yassine H, Ramirez JL, Taxiarchi C, Barillas-Mury C, et al. Plasmodium berghei P47 is essential for ookinete protection from the Anopheles gambiae complement-like response. Sci Rep. 2017;7:6026.

52. Rao PN, Santos JM, Pain A, Templeton TJ, Mair GR. Translational repression of the cpw-wpc gene family in the malaria parasite Plasmodium. Parasitol Int. 2016:65:463-71.

53. Modrzynska K, Pfander C, Chappell L, Yu L, Suarez C, Dundas K, et al. A knockout screen of ApiAP2 genes reveals networks of interacting transcriptional regulators controlling the Plasmodium life cycle. Cell Host Microbe. 2017;21:11-22.

54. Letunic I, Doerks T, Bork P. SMART 7: recent updates to the protein domain annotation resource. Nucleic Acids Res. 2012;40:D302-5.

55. Kelley LA, Mezulis S, Yates CM, Wass MN, Sternberg MJ. The Phyre2 web portal for protein modeling, prediction and analysis. Nat Protoc. 2015;10:845-58

56. Aurrecoechea C, Barreto A, Basenko EY, Brestelli J, Brunk BP, Cade S, et al. EuPathDB: the eukaryotic pathogen genomics database resource. Nucleic Acids Res. 2017;45:D581-91.
57. Ramaprasad A, Mourier T, Naeem R, Malas TB, Moussa E, Panigrahi A, et al. Comprehensive evaluation of Toxoplasma gondii VEG and Neospora caninum LIV genomes with tachyzoite stage transcriptome and proteome defines novel transcript features. PLOS ONE. 2015;10:e0124473.

58. Kou X, Zheng W, Du F, Liu F, Wang M, Fan Q, et al. Characterization of a Plasmodium berghei sexual stage antigen $\mathrm{PbPH}$ as a new candidate for malaria transmission-blocking vaccine. Parasit Vectors. 2016;9:190.

59. Wang DS, Shaw R, Winkelmann JC, Shaw G. Binding of PH domains of beta-adrenergic receptor kinase and beta-spectrin to WD40/betatransducin repeat containing regions of the beta-subunit of trimeric G-proteins. Biochem Biophys Res Commun. 1994;203:29-35.

60. Yao L, Kawakami Y, Kawakami T. The pleckstrin homology domain of Bruton tyrosine kinase interacts with protein kinase C. Proc Natl Acad Sci USA. 1994;91:9175-9.

61. Wang DS, Shaw G. The association of the C-terminal region of beta I sigma II spectrin to brain membranes is mediated by a PH domain, does not require membrane proteins, and coincides with a inositol-1,4,5 triphosphate binding site. Biochem Biophys Res Commun. 1995;217:608-15

62. Kumar P, Tripathi A, Ranjan R, Halbert J, Gilberger T, Doerig C, et al. Regulation of Plasmodium falciparum development by calcium-dependent protein kinase 7 (PfCDPK7). J Biol Chem. 2014;289:20386-95.

63. Brochet M, Collins MO, Smith TK, Thompson E, Sebastian S, Volkmann K, et al. Phosphoinositide metabolism links CGMP-dependent protein kinase $\mathrm{G}$ to essential $\mathrm{Ca}(2)(+)$ signals at key decision points in the life cycle of malaria parasites. PLoS Biol. 2014;12:e1001806.

64. Bullen HE, Jia Y, Yamaryo-Botte Y, Bisio H, Zhang O, Jemelin NK, et al. Phosphatidic acid-mediated signaling regulates microneme secretion in Toxoplasma. Cell Host Microbe. 2016;19:349-60.

65. Jacot D, Tosetti N, Pires I, Stock J, Graindorge A, Hung YF, et al. An Apicomplexan actin-binding protein serves as a connector and lipid sensor to coordinate motility and invasion. Cell Host Microbe. 2016;20:731-43.

66. Dessens JT, Saeed S, Tremp AZ, Carter V. Malaria crystalloids: specialized structures for parasite transmission? Trends Parasitol. 2011;27:106-10.

67. Saeed S, Tremp AZ, Dessens JT. Biogenesis of the crystalloid organelle in Plasmodium involves microtubule-dependent vesicle transport and assembly. Int J Parasitol. 2015;45:537-47.

68. Santos JM, Duarte N, Kehrer J, Ramesar J, Avramut MC, Koster AJ, et al. Maternally supplied S-acyl-transferase is required for crystalloid organelle formation and transmission of the malaria parasite. Proc Natl Acad Sci USA. 2016;113:7183-8.

69. Le SQ, Gascuel O. An improved general amino acid replacement matrix. Mol Biol Evol. 2008;25:1307-20.

70. Kumar S, Stecher G, Tamura K. MEGA7: molecular evolutionary genetics analysis version 7.0 for bigger datasets. Mol Biol Evol. 2016;33:1870-4.
Ready to submit your research? Choose BMC and benefit from:

- fast, convenient online submission

- thorough peer review by experienced researchers in your field

- rapid publication on acceptance

- support for research data, including large and complex data types

- gold Open Access which fosters wider collaboration and increased citations

- maximum visibility for your research: over 100M website views per year

At $\mathrm{BMC}$, research is always in progress.

Learn more biomedcentral.com/submissions 